\title{
Managing Unilateral Market Power in Electricity
}

\author{
Frank A. Wolak ${ }^{1}$ \\ Department of Economics \\ Stanford University \\ Stanford, CA 94305-6072 \\ e-mail: wolak@zia.stanford.edu \\ http://www.stanford.edu/ wolak
}

World Bank Policy Research Working Paper 3691, September 2005

The Policy Research Working Paper Series disseminates the findings of work in progress to encourage the exchange of ideas about development issues. An objective of the series is to get the findings out quickly, even if the presentations are less than fully polished. The papers carry the names of the authors and should be cited accordingly. The findings, interpretations, and conclusions expressed in this paper are entirely those of the authors. They do not necessarily represent the view of the World Bank, its Executive Directors, or the countries they represent. Policy Research Working Papers are available online at http://econ.worldbank.org.

\footnotetext{
${ }^{1}$ Professor of Economics and Chairman, Market Surveillance Committee, California Electricity Industry Independent System Operator. This paper was prepared as part of the research program on Industrial Organization Policy for Development at the Development Research Group of the World Bank, under the direction of Ioannis Kessides.
} 


\section{Introduction}

The past two decades of international experience with wholesale electricity markets has demonstrated that significant consumer harm can result from firms simply engaging in unilateral profit-maximizing behavior given the actions of their competitors. Different from other product markets, coordinated actions among suppliers or the concentration of production capacity in the hands of small number of firms is unnecessary for electricity suppliers to raise prices substantially above competitive levels. A number of wholesale electricity markets with Hirshman-Herfindahl Indexes (HHIs) that would not raise market power concerns if they were from other industries have been subject to severe market power problems. In addition, for all of these market power episodes, the relevant competition authorities have not found evidence of coordinated actions among suppliers to raise prices in violation of the competition or antitrust law. These facts provide strong evidence that competition or antitrust policy as it is applied to other industries may be insufficient to protect electricity consumers.

This paper argues that the technology of electricity production and remnants of the former monopoly regime imply that conventional competition policy must be augmented with an industry-specific regulator endowed with a pre-specified set of responsibilities. This combination of regulatory oversight and competition law will provide consumers with the same level of market power protection they receive for other products from conventional competition law. An industry-specific regulator is necessary because: (1) unilateral market power problems can be extremely difficult to predict, and (2) they can impose significant economic harm for a sustained period of time when they do occur. Moreover, how this unilateral market power is exercised and the harm it causes arise from a number of unique features of wholesale electricity markets. Clearly specified regulatory safeguards tailored to the electricity supply industry are needed to prevent the harmful exercise of unilateral market power before it can occur and rapidly implement the necessary remedies if it does occur. The primary goal of this regulatory process should be to prevent market participant behavior that significantly degrades system reliability and market efficiency.

It is important to emphasize that it is impossible for the regulator to prevent firms from exercising unilateral market power. In fact, markets function most efficiently when suppliers have high-powered incentives to exercise all available unilateral market power and there are few barriers to entry. The role of the regulatory process is to ensure that the conditions necessary for vigorous competition exist and to limit the economic harm associated with the exercise of unilateral market power when they do not exist. Regulatory mechanisms that attempt to prevent all exercise of unilateral market power can introduce market inefficiencies that cause more economic harm than the market power they are attempting to prevent.

This regulatory process should be self-correcting in the sense that there are pre-specified regulatory responses to certain market outcomes and market participant behavior that significantly degrades system reliability and market efficiency that are known to all market participants in advance. The aftermath of the events in the California electricity market from June 2000 to June 2001 and the Enron bankruptcy have demonstrated that ex regulatory intervention is extremely costly and very unlikely to remedy the harm done. This experience and similar ones from other markets around the world argue in favor of a prospective 
regulatory process that anticipates possible harmful market outcomes and builds in incentives for market participants to solve these problems without the need to formulate new regulatory policy. Rather than attempt to formulate this policy under the intense scrutiny that accompanies harmful market outcomes, a more prudent regulatory policy is to build in mechanisms that anticipate and address as many of these potential harms as possible.

The technology of electricity supply creates an additional reason, not relevant in other markets, to limit the exercise of unilateral market power and encourage market participants to obey the wholesale market rules. Because all electricity must be delivered through a common transmission network, the actions of some market participants can impact the ability of other market participants to buy or sell electricity. A regulatory process is necessary to ensure that the unilateral profit-maximizing behavior of each market participant does not significantly degrade the reliability of the transmission network. The regulatory process should therefore strive to make the market rules transparent to all market participants and as straightforward as possible to enforce. The experience of a number of wholesale electricity markets suggests that imprecise market rules that appear to prohibit a wide range of behavior may lead to a less reliable transmission network than seemingly less restrictive but more clearly defined market rules that are substantively more straightforward to monitor and enforce. I will present examples of imprecise rules that detract from system reliability and market efficiency, along with recommendations for increasing the precision and enforceability of these rules.

Because actions that earn some market participants substantial profits can impose significant harm to market efficiency and system reliability, there must be market rules prohibiting these sorts of actions. Enforcing these market rules without causing more harm than is cured is extremely difficult. The prime example of this phenomenon in electricity market oversight is distinguishing between the unilateral exercise of market power and the poorly defined, but often invoked, concept of market manipulation. The widespread use of this term to describe the behavior of certain market participants in wholesale electricity markets occurs precisely because the unilateral exercise of market power in this industry can cause substantial consumer harm. U.S. antitrust law contains no formal definition of market manipulation. However, the concept does have meaning in the U.S. in the context of formal securities and commodities markets, where it is defined by the market rules. Futures exchanges define certain actions by market participants, for example, corners and squeezes, as prohibited market manipulation. A necessary condition for a finding of market manipulation is that the market participant took the prohibited action with the intent to produce an outcome that significantly harmed other market participants. For example, a market participant may purchase a large position in the futures market and then take delivery on these contracts because of a genuine need for the commodity or because of a desire to corner the market. Building on the general framework used in financial markets, I propose a definition of market manipulation for wholesale electricity markets that the regulator should enforce, as well as an administrative process for the regulator to follow in order to make a finding of intent, the crucial step in a market manipulation determination. The goal of this administrative procedure is to limit economic harm due to deviations from price-taking behavior by market participants, not to detect and punish all instances of alleged market manipulation. 
The remainder of the paper proceeds as follows. The next section summarizes the reasons why the exercise of unilateral market power can cause so much harm in a seemingly competitive wholesale electricity market and why an industry specific regulator is essential to adequately addressing these market power problems. Section three describes the goal of the regulatory process and responsibilities of the industry-specific regulator. Section four describes guidelines for setting penalties and sanctions that ensure compliance with market rules. The fifth section suggests a mechanism for administering and enforcing a market rule prohibiting behavior harmful to system reliability and market efficiency. The paper closes with a discussion of the protocols for the competition authority to interact with the industryspecify regulator to provide maximal protection against the harmful market outcomes. This section also outlines a procedure for the relevant government authority to follow to phase out aspects of the industry-specific regulatory process as the wholesale market matures.

\section{Why Electricity is Different}

It is difficult to conceive of an industry more susceptible to the exercise of unilateral market power than electricity. It possesses virtually all of the product characteristics that enhance the ability of suppliers to exercise unilateral market power. Supply must equal demand at every instant in time and each location of the network. It is very costly to store and production is subject to extreme capacity constraints in the sense that it is impossible to get more than a pre-specified amount of energy from a given generation unit in an hour. Delivery of the product consumed must take place through a potentially congested transmission network. Historically, how it has been priced to final consumers makes the wholesale demand extremely inelastic, if not perfectly inelastic, with respect to the wholesale price. The technology of electricity production historically favored large generation facilities, and in most wholesale markets the vast majority of these facilities are owned by a relatively small number of firms. Finally, generation capacity ownership also tends to be concentrated in small geographic areas within these regional wholesale markets. All of these factors also make wholesale electricity markets substantially less competitive the shorter the time lag is between the date the sale is negotiated and the date delivery of the electricity occurs.

Electricity suppliers possess differing degrees of system-wide and local market power. System-wide market power arises from the capacity constraints in the production and the inelasticity of the aggregate wholesale demand for electricity, ignoring the impact of the transmission network. Local market power is the direct result of the fact that all electricity must be sold through a transmission network with finite carrying capacity. The geographic distribution of generation ownership and demand interact with the structure of the transmission network to create circumstances when a small number of suppliers or even one supplier is the only one able to meet an energy need at a given location in the transmission network. A supplier that is a monopolist or duopolist for a local energy need possesses substantial local market power.

The distinction between system-wide and local market power is often blurred by the choice of the relevant market. If electricity did not need to be delivered through a potentially congested transmission network subject to line losses, then it is difficult to imagine that any supplier could possess substantial system-wide market power in a market comprised of the entire US. Consequently, the market power that an electricity supplier possesses is a 
function of the size of the geographic market it competes in, which depends on the characteristics of the transmission network and location of final demand.

These two determinants of market power imply that a supplier possesses local market power regardless of the congestion management protocols used by the wholesale market. In single-price markets, zonal-pricing markets and nodal-pricing markets, local market power arises because the existing transmission network does not provide the supplier with sufficient competition to discipline its bidding behavior into the wholesale market. This is particularly the case in the US, where the rate of investment in the transmission network has persistently lagged behind the rate of investment in new generation capacity over the past 25 years.

Most of the existing transmission network in the U.S. was designed to support a vertically-integrated utility regime that no longer exists. Particularly around large population centers and in geographically remote areas, the vertically-integrated utility used a mix of local generation units and transmission capacity to meet the annual demand for electricity in the region. Typically, the utility supplied the region's baseload energy needs from distant inexpensive units using high-voltage transmission lines. It used expensive generating units located near the load centers to meet the periodic demand peaks throughout the year. This combination of local generation and transmission capacity to deliver distant generation was the least-cost strategy for serving the utility's load in the former regime.

The transmission network that resulted from this strategy by the vertically integrated utility creates local market power problems in the new wholesale market regime because now the owner of the generating units located close to the load center may not own, and certainly does not operate, the transmission network. The owner of the local generation units is often not even the load-serving entity (LSE) for that geographic area. Consequently, during the hours of the year when system conditions require that some energy be supplied from these local generation units, it is profit-maximizing for the owner to bid whatever the market will bear for any energy these units provide. This incentive exists regardless of the locational pricing scheme used by the wholesale market operator.

This point deserves emphasis: Absent a local market power mitigation mechanism, the bid of the unit or units with local market power must be taken before lower-priced bids from other firms. The configuration of the transmission network and location of demand makes this unit the only one physically capable of meeting the energy need. Without some form of regulatory intervention, these suppliers will be paid at least their bid price to provide the needed electricity willingly. The configuration of the existing transmission network and the geographic distribution of generation capacity ownership in all US wholesale markets and a number of wholesale markets around the world results in a frequency and magnitude of substantial local market power for certain market participants that if left unmitigated could earn these firms enormous profits and therefore cause substantial harm to consumers.

The uncertain availability of generation units and portions of the transmission network because of forced outages implies that system conditions can arise when virtually any generation unit owner in the wholesale market possesses substantial local market power. Consequently, a local market power mitigation (LMPM) mechanism that provides effective 
bid mitigation is a necessary component of any wholesale market design. The need for an effective LMPM mechanism is one unique feature of wholesale electricity markets that makes an industry-specific regulator essential at least during the initial stages of the transition from the vertically-integrated utility to the wholesale market regime.

A second rationale for an industry-specific regulator during the transition period is the potential for small market design flaws that cause little harm during most system conditions to lead to substantial consumer harm under certain system conditions. The experience of the California market from when it began operation to the present time illustrates this point. From its start in April 1998 until April 2000, the California market was probably the most competitive wholesale market in the US. Average wholesale prices over this period were less than $\$ 35 / \mathrm{MWh}$ and the average hourly magnitude of the market inefficiencies as measured by the methodology given in Borenstein, Bushnell and Wolak (2002), hereafter BBW, was less than or very close to equal to those measured by Mansur (2003) for the PJM market (serving some or all of the states Pennsylvania, New Jersey, Maryland, Delaware, and Virginia) and Bushnell and Saravia (2003) for the New England market. This level of market performance occurred in spite of the fact that virtually all of the wholesale energy purchases by the three large California retailers were made through the day-ahead or real-time market.

The amount of hydroelectric energy available from the Pacific Northwest during the summer of 2000 was significantly less than the previous two summers. Consequently, as documented in Wolak (2003a), the five largest fossil fuel electricity suppliers in California now faced significantly less elastic residual demand curves than they did during first two years of the market. As a consequence, these suppliers found it in their unilateral interest to bid less aggressively into the spot market in order to raise wholesale electricity prices in California. As discussed in Wolak (2003b), this strategy was not unilaterally profitable during the first two years of the market because the greater availability of hydroelectric energy from the Pacific Northwest and inexpensive coal-fired energy from the Desert Southwest during that time period caused these suppliers to face significantly more elastic residual demand curves.

This change in competitive conditions during the summer of 2000 enabled in-state suppliers to raise prices substantially through their unilateral actions, as demonstrated in BBW (2002). For example, during the summer months of June to September of 2000, the average difference between the actual price and the competitive benchmark price was more than $\$ 70 / \mathrm{MWh}$, which is more than twice the average price of electricity during the first two years of the market. The California experience demonstrates that some market design flaws, in this case insufficient forward contracting by electricity retailers, can be relatively benign under a range of system conditions. However, when system conditions conducive to the exercise of unilateral market power occur, this market design flaw can cause enormous harm to consumers. Consequently, industry-specific regulatory oversight is necessary to intervene as quickly as possible to limit the potential damage when these system conditions arise.

While it is not possible to rule out coordinated actions among the major electricity suppliers in the Western Electricity Coordinating Council (WECC) as a potential explanation for the enormous increase in wholesale prices over the period June 2000 to June 2001, as 
shown in Wolak (2003a), this is not necessary. The behavior of prices during this time period relative to the first two years of operation of the market can be explained by the unilateral profit-maximizing actions of the major California fossil fuel suppliers given the residual demand curves they faced. Despite extensive multi-year investigations by almost every state-level antitrust and regulatory commission in the western US, the US Department of Justice Antitrust Division, the Federal Energy Regulatory Commission, and numerous Congressional committees, no significant evidence of coordinated actions to raise wholesale electricity prices in the WECC during the period June 2000 to June 2001 has been uncovered.

From the perspective of antitrust law, the most surprising aspect of the period June 2000 to June 2001 in the California market is that despite estimated total market inefficiencies of close to $\$ 20$ billion, virtually all of which was due to the exercise of unilateral market power, US antitrust law did little to prevent this enormous wealth transfer from occurring. Moreover, following the Enron bankruptcy and disclosure by a number of energy trading firms (in very unflattering terms) that they did attempt to exercise all available unilateral market power in the California market, US antitrust law has been unable to obtain refunds of any of these market power profits. This outcome has occurred because US antitrust law does not prohibit firms from fully exploiting their unilateral market power. Because of the enormous potential harm from the exercise of unilateral market power in electricity, other regulatory safeguards are necessary.

Besides the need to intervene to correct market design flaws after they are determined to be harmful, there is also a need to engage in prospective market monitoring to find market design flaws that lead to substantial harm by less noticeable means. For example, certain aspects of the wholesale market design can increase the likelihood that coordinated actions to raise prices might occur. Aspects of the market design can also enhance the ability of suppliers to exercise their unilateral market power. This logic suggests that another important role for an industry-specific regulator is to monitor the wholesale market to determine which market rules might be enhancing the ability of suppliers to exercise unilateral market power or increasing the likelihood that the attempts of suppliers to coordinate to raise market prices will be successful. Particularly, during the initial stages of the wholesale market regime, this prospective approach to regulatory oversight should implement market rule changes before they expose consumers to significant harm.

This role for the industry-specific regulator also has a pedagogical component. The transition to a wholesale market regime involves a dramatic change in behavior by a number of market participants. Companies that fail to adapt to the new regime are very likely to go bankrupt and exit the industry, but there are often significant external costs to consumers associated with this outcome. Consequently, an industry-specific regulator can take prospective actions to encourage to adaptation to the new regime and limit the resulting external costs if this change in market participant behavior does not occur. An example of a necessary change in behavior is the need for retailers to hedge spot price risk, something that was unnecessary in the former vertically-integrated regime because electricity retailers typically owned enough generation capacity to meet their load obligations. A significant regulatory challenge in a number of markets around the world is how to provide strong incentives for retailers to engage in the efficient amount of forward contracting, while at the same time not exposing consumers to sustained periods of very high spot prices. A purely 
market-based solution would be to expose retailers to risk of bankruptcy by having extremely high price caps or bid caps on the spot market. The fear of bankruptcy associated with a sustained period of extremely high spot prices when the retailer has a significant spot market exposure will cause retailers to engage in the appropriate amount of hedging of spot price risk. This strategy has worked remarkably well in Australia, where the bid cap on the spot market was $\$ 5,000 / \mathrm{MWh}$, and has recently been raised to $\$ 10,000 / \mathrm{MWh}$. Spot prices at or near these levels occasionally occur, but because of the high levels of forward contracting by Australian retailers these prices do not cause significant harm to consumers.

In the U.S. and New Zealand there have been a number of bankruptcies of large retailers as a result of a sustained period of very high spot prices that occurred when the retailer had a significant exposure to the spot market. Over-reliance on the spot market by retailers in the US is not surprising given the decision of the Federal Energy Regulatory Commission (FERC), the US wholesale market regulator, to impose hour-by-hour market power mitigation in the form of relatively low bid or price caps on the spot market and automatic mitigation procedures (AMP) that set very low bid caps for specific generation units. This mitigation limits the volatility and level of spot prices, which dulls the incentive for retailers to sign forward contracts or engage in other hedging arrangements to limit their exposure to the spot market. Consequently, regulatory invention to limit the volatility of spot prices creates the need for regulatory intervention to mandate that retailers purchase a portfolio of financial contracts to hedge their spot price risk. Particularly for the US, where retail market regulation is the domain of the state regulatory commissions and wholesale market regulation the domain of FERC, this strategy by FERC may be necessary to gain the consent of the state regulator to relax its control over retail electricity prices. Forward contracting requirements on electricity retailers are a part of virtually all Latin American markets. The industry-specific regulator typically mandates forward contracting requirements for retailers at various time horizons in advance of delivery to ensure there is adequate generation capacity to serve demand and that no retailers are overly exposed to the spot market.

Regulating forward contracting levels has an additional spot market competitiveness benefit. If these purchases are structured as fixed-price forward contracts for fixed amount of energy in the hour, they have very beneficial impacts on the competitiveness of shorterterm energy markets. As discussed in Wolak (2000a), forward contract obligations by a supplier make it unilateral profit-maximizing to bid more aggressively in the spot market. Moreover, Wolak (2000a) also emphasizes that forward contract obligations by one supplier can make it unilaterally profit-maximizing for other suppliers to bid more aggressively, regardless of their own forward contract holdings. The most successful wholesale electricity markets, as judged by the competitiveness of their spot markets, are those with where only a very small fraction of the total amount of electricity consumed is actually purchased in the spot market.

The final rationale for an industry-specific regulator arises because the technology for supplying electricity implies the need for a single transmission and distribution network for a given geographic area. Even after accounting for the distortions from least-cost supply in setting regulated prices for these services, regulated monopoly provision is generally acknowledged to have a lower overall cost than competitive provision of transmission and distribution services for a given geographic area. Regulated monopoly provision implies the 
need for a regulator to set the price that wholesale and retail market participants pay for access to the transmission and distribution network. These prices must also allow the network owners to recover the cost of past investments, the ongoing cost of operating the network and the cost of future investments necessary to serve a growing demand for electricity. This task requires the regulator to have significant industry-specific expertise.

There are also important market competitiveness benefits from regulatory oversight of the transmission network. They are determining the terms of conditions for new generation units to interconnect to the transmission network and whether transmission upgrades should take place and where they should take place. As discussed in Wolak (2003c), in the wholesale market regime transmission capacity has an additional role as a facilitator of commerce. Expansion of the transmission network typically increases the number of independent wholesale electricity suppliers that are able to compete to supply electricity at locations in the transmission network served by the upgrade. The industry-specific regulator is best-suited to develop the expertise necessary to determine the transmission network that maximizes the competitiveness of the wholesale electricity market. With the exception of the US, most countries re-structured at a time when they had significant excess transmission capacity, so the issue of how to expand the transmission network to serve the best interests of wholesale market participants has not yet become significant. In the US, determining how to expand the transmission network to serve the needs of wholesale market participants has been a major stumbling block to realizing the expected benefits of electricity industry restructuring.

\section{Responsibilities of Industry-Specific Regulator}

\section{Goal of Regulatory Process}

This section first states the primary goal of the regulatory process and then sets out the major responsibilities of the industry-specific regulator. Because electricity markets are so susceptible to the exercise of unilateral market power, the primary goal of the industryspecific regulatory process is to limit the ability of market participants to engage in behavior that degrades system reliability and market efficiency, the two major adverse consequences of the exercise of market power.

As noted earlier, it is impossible to prevent firms from exercising all available unilateral market power. This would imply the existence of a perfect regulatory process. The market or system operator would need to know each supplier's minimum cost of producing power. It could then dispatch suppliers based on their minimum cost of producing power. However, if such a regulatory process existed there would be little need to introduce a competitive market because, by assumption, a lower average cost of supplying power to consumers could be achieved by paying suppliers only their minimum cost of production, rather than the market-clearing price set through a process where all suppliers bid to maximize their expected profits for all of the energy they produce. Consequently, any mechanism used to mitigate market power is necessarily imperfect in the sense of being unable to protect consumers from the exercise of all market power. 
By the same logic, there are no perfectly competitive markets. However, there are many markets that yield outcomes very close to those predicted by the perfectly competitive ideal. Unfortunately, electricity is not always one of these markets. Consequently, the market designer is typically faced with the choice between an imperfectly competitive market and an imperfect regulatory mechanism to set the compensation paid to a firm. A social welfare maximizing market designer would make this choice based on which mechanism entails the smallest loss in social welfare.

This logic implies a regulatory process that provides incentives for efficient market outcomes, instead of focusing on preventing firms from exercising all unilateral market power. The regulatory process should provide the strongest possible incentives for least-cost provision of electricity to final consumers consistent with the long-term financial viability of the industry. Running a regulatory process is costly and regulatory invention even more so. Therefore, it is important to account for these costs in the design and operation of the regulatory process. Specifically, the regulatory process should first focus on actions that have a very high market efficiency benefits relative to their implementation costs. The regulator should also periodically review the costs and benefits all of aspects of the regulatory process.

\section{Three Major Responsibilities of Regulatory Process}

I will now describe the three major responsibilities of the industry-specific regulator and how these should be carried out. They are: (1) disseminating information to existing and prospective market participants, (2) ensuring compliance with all the market rules, and (3) protecting against behavior that degrades market efficiency and system reliability. Successfully fulfilling each role requires much greater regulatory authority and sophistication on the part of the regulatory process than the previous one.

\section{Smart "Sunshine Regulation"}

A minimal requirement of any industry-specific regulatory process is to provide "intelligent sunshine" regulation. The regulator must have access to all information needed to operate the market and be able to perform analyses of this data and release the results to the public. At the most basic level, the regulator should be able to replicate market-clearing prices and quantities given the bids submitted by market participants, total demand, and other information about system conditions. This is necessary for the regulator to verify that the market is operated in a manner consistent with what is written in the market rules. A second aspect of "smart sunshine regulation" is public data release. Specifically, all data submitted to real-time market and produced by the system operator should be immediately released to the public. Little trading of energy should take place through the real-time market, because it is operated primarily for reliability reasons and all market participants have a common interest in the reliability of the transmission network. Immediate data release best serves these reliability needs.

There should be no limitation on the regulator's access to data either submitted to the system operator by market participants or produced by the system operator. Besides all of the information needed to operate the energy and ancillary services markets and the 
transmission network, the regulator should also have the ability to request information from market participants on a confidential basis to perform further analyses. Rather than have an ex ante limitation on the type of data it can request, the regulator should have open-ended authority to request information subject to an economic cost-benefit test. To enforce this authority, the regulator should also have the ability to impose financial penalties on market participants that fail to provide the requested data in a reasonable period of time.

Wholesale markets that currently exist around the world differ considerably in terms of amount of data they make publicly available and the lag between the date the data is created and the date it is released to the public. Nevertheless, among the industrialized countries there appears to be a positive correlation between the extent to which data submitted or produced by the system operator is made publicly available and how well the wholesale market operates. For example, the Australian electricity market makes all data on bids and unit-level dispatch publicly available the next day. Australia's National Electricity Market Management Company (NEMMCO) posts this information by market participant name on its website. The Australian electricity market is generally acknowledged to be one of the best performing re-structured electricity markets in the world (Wolak1999). On the other hand, the former England and Wales electricity pool kept all of the unit-level bid and production data confidential. Only members of the pool could gain access to this data. It was generally acknowledged to be subject to the exercise of substantial unilateral market power by the larger suppliers (Wolak and Patrick 1997 and Wolak 1999). The UK government's displeasure with pool prices eventually led to the New Electricity Trading Arrangement (NETA) which began operation on March 27, 2001. Although these facts do not provide definitive proof that rapid and complete data release enhances market efficiency, the best available information on this issue provides no evidence that withholding this data from the public scrutiny enhances market efficiency.

The public data release should identify the market participant and specific generation unit associated with each bid, generation schedule, or output level. Masking the identity of the market participants, as is done in all US wholesale markets, limits the disciplining value of public data release on market participant behavior. Under a system of masked data release, market participants can always deny that their bids or energy schedules are the ones exhibiting the unusual behavior. The primary value of public data release is putting all market participants at risk for explaining their behavior to the public. In all US markets, the very long lag between the date the data is produced and the date it is released to the public, at least six months, and the fact that the data is released without identifying the specific market participants, virtually eliminates much of the potential benefit of public data release.

Putting market participants at risk for explaining their behavior to the public is different from requiring them to behave in a manner that it is inconsistent with their unilateral profitmaximizing interests. A number of markets have considered implementing "good behavior conditions" on market participants. The most well-known attempt was the United Kingdom's (UK) consideration of a Market Abuse License Condition (MALC) as a precondition for participating in its wholesale electricity market. The fundamental problem with these "good behavior" clauses is that they can prohibit behavior that is in the unilateral profit-maximizing interests of a supplier that is also in the interests of consumers. These "good behavior" clauses do not correct the underlying market design flaw or implement a 
change in the market structure to address the underlying cause of the harm from the unilateral exercise of market power. They simply ask that the firm be a "good citizen" and not maximize profits.

For the case of the U.K., the MALC anticipated punishing those market participants that exercised significant amount unilateral market power. However, one difficulty with this approach is that the major beneficiaries of the unilateral exercise of market power are the firms that exercised little if any unilateral market power. One could therefore imagine some firms finding ways to compensate larger firms for exercising their unilateral market power so that all firms can reap benefits. A second difficulty is distinguishing the exercise of significant market power worthy of punishment from expected profit-maximizing behavior. In testimony to the United Kingdom Competition Commission, Wolak (2000b) made these and a number of other arguments against the MALC, which the Commission eventually decided not to implement.

Another potential benefit associated with public data release is that it enables thirdparties to undertake analyses of market performance. The US policies on data release severely limit the benefits from this aspect of a public data release policy. Releasing data with the identities of the market participant masked makes it impossible to definitively match data from other sources to specific market participants. For example, some market performance measures require matching data on unit-level heat rates or input fuel prices obtained from other sources to specific generation units. Strictly speaking, this is impossible to do if the unit name or market participant name is not matched with the generation unit.

The long time lag between the date the data is produced and the date it is released also greatly limits the range of questions that can be addressed with this data. Taking the example of the California electricity crisis, by January 1, 2001, the date that masked data from June of 2000 was first made available to the public, the exercise of unilateral market power in California had already resulted in more than $\$ 5$ billion in overpayments to suppliers in the California electricity market as measured by BBW (2002). Consequently, a long time lag between the date the data is produced and the date it is released to the public has an enormous potential cost to consumers that should be balanced against the benefits of delaying the data release.

The usual argument against immediate data release is that suppliers could use this information to coordinate their actions to raise market prices through sophisticated tacit collusion schemes. Although the immediate availability of information on bids, schedules and actual unit-level production could allow suppliers to design more complex statedependent strategies for enforcing collusive market outcomes, it is important to bear in mind that coordinated actions to raise market prices are illegal under US anti-trust law and under the competition law in virtually all countries around the world. The immediate availability of this data means that the public also has access to this information and can undertake studies examining the extent to which market prices difference competitive benchmark levels as described in BBW (2002). Keeping this real-time data confidential prevents this potentially important form of public scrutiny of market performance from occurring. 
This data can also be used to undertake third-party studies of whether coordinated actions, explicit or tacit, are occurring. Although these third parties would find it difficult to produce evidence of explicit or tacit collusion that would lead to a conviction in a court of law, they only need to present evidence that has a high likelihood of yielding a conviction in the court of public opinion. The prospect of such adverse publicly is very likely to increase the perceived cost to market participants of engaging in explicit or tacit co-ordinated behavior to raise market prices. Despite a prohibition against conscious parallelism in under US antitrust law, I am not aware of a successfully prosecuted lawsuit against such behavior in any industry in the U.S. Consequently, the fear of a conviction in the court of public opinion appears to be best way to prevent such behaviour.

Economic theory provides no clear predictions about the relationship between the information made available to market participants and their ability to implement less competitive market outcomes. A number of theoretical papers have identified circumstances when asymmetric information between market participants can be a very effective device for implementing less competitive market outcomes, through either unilateral or co-ordinated actions. I am also not aware of any systematic empirical evidence industries demonstrating that making more information available to market participants leads to less competitive market outcomes.

Coherent arguments in favor of masking the identity of market participants in the publicly released bid, schedule and production data are more difficult to find. Assuming that the concerns with public data release enhancing the ability of market participants to coordinate actions had been addressed, it is difficult to determine what market efficiencyenhancing benefit results from masking the identity market participants. Masking the identity of the market participant only limits the "sunshine regulation" value of public data release.

An important aspect of the public data release question is the distinction between data that the regulator can request and receive from market participants and data that must be released to the public. There is a natural boundary between these two types of data. Any data that the system operator must request from market participants or must produce in order to operate the real-time market should be released to the public. As noted earlier, the real-time market is operated primarily for reliability reasons and this data release policy is consistent with the goal of preventing harm to system reliability and market efficiency.

Public release of any information on forward market positions or transactions prices, where the large volumes of energy are typically traded, does not serve this goal. This is information about a market participant that is unnecessary to operate the real-time market, although it does impact the bidding, scheduling or production behavior of that market participant, as discussed in Wolak (2000a). Knowledge of these financial positions is not needed by the system operator to run the spot market or the transmission network.

Because of the fundamentally financial nature of forward market transactions sold by electricity suppliers, it is very difficult to get accurate information on the true forward market positions of electricity suppliers. They can re-trade forward market obligations among themselves to yield forward market positions far above or below their expected 
production of electricity. A number of studies of electricity trading in the US before by Enron bankruptcy in late 2001 estimated that each electron ultimately delivered through a US wholesale electricity market was bought and sold in forward markets more than five times. For this reason, even if the regulator attempted to collect this forward market data from suppliers on a regular basis it would not be very useful. For example, if the regulator specified a minimum quantity of forward contract sales for each supplier it regulated, these suppliers could undertake forward contract transactions with affiliates not subject to regulatory oversight to meet these minimums. Moreover, those affiliates not subject to oversight by the regulator could then re-construct their holding company's desired forward contract position. Consequently, routinely collecting the forward contract positions of suppliers could cause them to render this information of little or no use to the regulator through affiliate transactions.

There is a strong argument for keeping any forward contract positions the regulator might collect confidential. As noted in Wolak (2000a), the financial forward contract holdings of a supplier are major determinants of the aggressiveness of its bids into the spot market. Only if a supplier is confident that it will produce more than its forward contract obligations will it have an incentive to bid or schedule its units to raise the market price. Suppliers recognize this incentive created by forward contracts when they bid against competitors with forward contract holdings. Consequently, public disclosure of the forward contract holdings of market participants can convey useful information about the incentives of individual suppliers to raise market prices, with no countervailing reliability or marketefficiency enhancing benefits.

A final aspect of the data collection portion of the regulatory process is concerned with scheduled outage coordination and forced outage declarations. A major lesson from wholesale electricity markets around the world is the impossibility of determining whether a unit that is declared out-of-service can actually operate. Different from the former vertically integrated regime, declaring a "sick day" for a generation unit--saying that it is unable to operate when in reality it could safely operate--can be a very profitable way for a supplier to withhold capacity from the market in order to raise the wholesale price. To limit the ability of suppliers to use their planned and unplanned outage declarations in this manner, the market operator and regulator must specify clear rules for determining a unit's planned outage schedule and for determining when a unit is forced out.

Before the start of each year, suppliers should submit to the system operator a schedule of planned outages for each of their units. The system operator would then compile the planned outage schedules submitted by all suppliers and verify that they do not compromise system reliability. If they do, then the system operator will suggest modifications to achieve a schedule of planned outages for all units consistent with reliable network operation on annual basis. Although the system operator should attempt to accommodate the wishes of each supplier, it must have the ultimate authority to set the final schedule for all planned outages. Once this planned outage schedule is set, it should be released to the public. Modifications of these unit-level planned outages schedules during the year are subject to the approval of the system operator. These modifications should be released to the public once they are approved. 
A similar process should be followed for scheduling planned transmission line outages. The system operator should coordinate the planned transmission outage process with all of the transmission owners and the generation unit owners. It should also make the final decision on when both generation units and transmission lines can be taken out for maintenance.

To limit the incentive for "sick day" unplanned generation outages, the system operator should specify the following scheme for outage reporting. Unless a unit is declared available to operate up to its full capacity, the unit is declared fully out or partially out depending on the amount capacity from the unit bid into the market at any price at or below the current price cap. This definition of a forced outage eliminates the problem of determining whether a unit that does not bid into the market is actually able to operate. Such a unit should be assumed to be forced out, because the owner is not offering this capacity to the market. The system operator should therefore only count capacity from a unit bid in at a price at or below the price cap as available capacity. Information on unit-level forced outages according to this definition should be publicly disclosed each day on the system operator's web-site.

This disclosure process cannot prevent a supplier from declaring a "sick day" to raise the price it receives for other energy or ancillary services that it sells. However, the process can make it more costly for the market participant to engage in this behaviour by registering all hours when capacity from a unit is not bid into the market as forced outage hours. For example, if a $100 \mathrm{MW}$ generation unit is neither bid nor scheduled in the spot market during an hour, then it is deemed to be forced out for that hour. If this unit only bids $40 \mathrm{MW}$ of the $100 \mathrm{MW}$ at or below the price or bid cap during an hour, then the remaining $60 \mathrm{MW}$ is deemed to be forced out for than hour. The regulator can then periodically report forced outage rates based on this methodology and compare these outage rates to historical figures from these units before re-structuring or from comparable units from different wholesale markets.

If the wholesale market makes capacity payments to generation units, then the amount of capacity a unit owner is allowed to sell should be based on the capacity of the unit multiplied by the 12-month rolling average of availability factor of the unit computed based on these outage rates. For example, if the $100 \mathrm{MW}$ unit only bids into the market during half of the hours of the year, then it should only be allowed to sell $50 \mathrm{MW}$ of capacity, because this is the average amount of capacity the unit provides to the market.

A similar process should be followed for unplanned transmission line outages. The regulator should compile information on the hourly amount of available transmission capacity. As soon as outages or de-ratings occur, this information should be made publicly available. The regulator should also compile the annual distribution of hourly transmission capacity availability and make this information publicly available. This information can also be used by the regulator and system operator to implement penalty and sanctions schemes for transmission owners that fail to maintain their transmission facilities in a manner consistent with good utility practice. 


\section{Ensuring Compliance with Market Rules}

Many market outcomes that are harmful to system reliability and market efficiency could be prevented if all market participations fulfilled all of their contractual obligations. Because the actions of each market participant impact system reliability and market efficiency, this implies that all parties have a common interest in honoring their contractual obligations. If the cost of violating a contractual commitment or market rule is less than the unilateral benefit from this action, the market participant will find it profitable to violate, which also adversely impacts system reliability and market efficiency. This logic implies that the second responsibility of the regulatory process is to: (1) design market rules to resemble publicly verifiable contractual obligations, and (2) determine the appropriate penalties and sanctions to deter violations of these rules without adversely impacting market efficiency or system reliability.

Not all market rules are defined to resemble publicly verifiable contractual obligations. Prohibitions against market manipulation or the abuse of market power are prime examples. These prohibitions have done very little to prevent harmful market outcomes. The California market rules contained these prohibitions, but they did little to prevent the events of June 2000 to June 2001. The third responsibility of the regulatory process is to prevent harmful market outcomes that cannot be prevented by market participants obeying market rules that resemble publicly verifiable contractual obligations.

A large fraction of harmful market outcomes can be prevented and the costs of operating the market and the costs of participating in the market will be lower if all market participants are confident that all contractual commitments will be honored regardless of system conditions. Contract enforcement costs stem from ambiguous or overly broad market rules or market rules that are not, or cannot be, enforced. A transparent rule that can be rigorously enforced is superior to an overly broad rule that is difficult to enforce. Irregular enforcement, either because of imprecise rules or inconsistent effort, increases the cost of market participation. This can also lead to increased market rule violations as more market participants push the boundaries of acceptable behavior.

This logic implies that regulator should divide market rules into two categories: (1) those that resemble publicly verifiable contractual obligations with little subjective judgement to determine compliance, and (2) those that require a formal administrative process to determine compliance. Rules in first category should be written to limit ambiguity and simplify enforcement. Those in the second category should have pre-specified administrative processes that deter behavior harmful to system reliability and market efficiency because of the large amount of judgement associated with determining a violation has occurred.

The first type of market rule should be written so that a violation resembles the process of issuing a speeding ticket as closely as possible. If the regulator measures the speed of the car using a publicly verifiable measuring device and finds that the car's speed exceeds the posted limit, then the regulator should assess a pre-specified penalty. The penalties and sanctions process should not involve a finding of intent in order for the regulator to assess a penalty. An example of a market rule violation covered by this mechanism is a failure to 
comply with terms implied by a bid into the wholesale market. One example is a market participant submitting a bid to supply a fixed quantity of energy within a given response time and then failing to meet this commitment. Suppose the supplier bids to provide 50 MWh of energy in 10 minutes from the time the bid is accepted. If the supplier fails to provide any of the purchased energy when it is called upon, the unit owner should be penalized for failing to meet this contractual commitment.

Both types of market rules require penalty and sanction mechanisms, but for slightly different purposes. In both cases, penalties and sanctions are imposed to deter market rule violations. For the market rules where determining compliance is straightforward, the penalties and sanctions are the primary mechanism for deterring violations. For case where subjective judgement is required to determine a violation, the penalties and sanctions are the ultimate backstop, but the administrative process is the primary mechanism for preventing harmful market outcomes.

\section{Protecting against Behavior Harmful to Market Efficiency and System Reliability}

The final responsibility for the regulator is to deter behavior that is harmful to system reliability and market efficiency that occurs despite public disclosure of data and market participant behavior and penalties for publicly-observed, objective market rule violations. This is the most complex aspect of the regulatory process to implement, but it also has the potential to yield the greatest benefit. It involves a number of inter-related tasks. In a bidbased market, the regulator must design and implement a local market power mitigation mechanism. The regulator must also determine when a market rule detracts from system reliability and market efficiency and suggest and implement the necessary changes in this market rule. The regulator must determine when market outcomes cause enough harm to some market participants to merit explicit regulatory intervention. Finally, if the market outcomes become too harmful, the regulator must have the ability to temporarily suspend market operations. All of these tasks require a substantial amount of subjective judgement on the part of regulator.

Local Market Power Mitigation (LMPM) Mechanism. In all bid-based electricity markets a local market power mitigation mechanism is necessary to limit the bids a supplier submits when it faces is insufficient competition to serve a local energy need. An LMPM mechanism is a pre-specified administrative procedure (usually written into the market rules) that determines: (1) when a supplier has local market power worthy of mitigation, (2) what the mitigated supplier will be paid, and (3) how the amount the supplier is paid will impact the payments received by other market participants. It is increasingly clear to regulators around the world, particularly those that operate markets using Locational Marginal Pricing (LMP), that formal regulatory mechanisms are necessary to deal with the problem of insufficient competition to serve certain local energy needs.

Formulate and Implement Efficiency-Enhancing Market Rule Changes. The regulator must determine which market rules detract from market efficiency or system reliability and formulate and implement the appropriate market rule changes. Because the level and geographic distribution of demand, the mix of input fuels used and ownership shares for generation capacity in the control area, and the configuration of the transmission network 
can all change over time, market rules must also change. The regulator must continually analyze and assess the market efficiency impacts of all market rules. Once it has identified a deficient market rule, the regulator must then work with the system and market operators to devise the necessary remedy. This duty underscores the need for the regulator to analyze market performance using the data it has compiled.

Penalize Behavior Harmful to System Reliability and Market Efficiency. The regulator is the first line of defense against harmful market outcomes. Persistent behavior by a market participant that is harmful to market efficiency or system reliability should be subject to penalties and sanctions. In order to assess these penalties, the regulator must determine first intent on the part of the market participant. The market rules should contain a general provision prohibiting persistent behavior detrimental to system reliability and market efficiency. The goal of this provision is to establish a process for the regulator to intervene to prevent a market meltdown. As shown in Wolak (2003a), there are instances when actions very profitable to one or a small number of market participants can be extremely harmful to system reliability and market efficiency. A well-defined process must exist for the regulator to intervene to protect market participants and correct the market design flaw facilitating this harm. This provision protects against the harmful exercise of unilateral market power, which is distinct from the exercise of unilateral market power, which is equivalent to maximizing profits. The discussion in Section 5 states that besides a finding of "intent", the regulator must also find "significant harm" for violation of this market rule to occur.

Determine When Market Activities Can Be Temporarily Suspended. The regulator must have the ability to suspend market operations on a temporary basis when system conditions warrant it. The suspension of market operations should only occur after a pre-specified administrative procedure has been followed and it has been determined that it is the only option available to the regulator to prevent significant harm to market efficiency and system reliability. As has been demonstrated in various countries around the world, electricity markets can sometimes become wildly dysfunctional and impose enormous harm over a very short period time. For example, during the early stages of the New England market, there were short-lived, but severe distortions in the Installed Capacity and Operating Capacity markets that eventually lead to a suspension of market activities. During the California market's first summer, one of the reserve capacity markets experienced extremely high prices for a short period. During the initial stages of the wholesale market in the state of Queensland in the Australia, unilateral market power problems became so severe that it was necessary to suspend market operations under sufficient interconnection capacity with neighboring states and generation capacity within the state could be built. Under these sorts of circumstances, the regulator should have the ability to suspend market operations temporarily until the problem can be dealt with through a longer-term regulatory intervention or market rule change. 


\section{Guidelines for Setting Penalties and Sanctions}

This section presents three guidelines for designing penalty and sanctions mechanisms for ensuring market participant compliance with market rules.

The first guideline is that the penalty for a market rule violation should be sufficiently high to make it unilaterally unprofitable for a market participant to violate the rule. The strategy used by FERC until very recently of limiting the magnitude of the penalty to ordering the firm that violated the market rule to return the profits gained from their violation will not deter violations. Under this scheme, firms would have little to lose from violating rules because their violation may not be detected and, even if it is detected, they are not made any worse off than if they had followed the rules in the first place.

The second guideline is that the mechanisms for imposing penalties and sanctions should be set in advance and the relationship between a specific market rule violation and the amount of the penalty assessed should be as transparent as possible. Returning to the above example of failing to comply with a dispatch instruction, the system operator could require that the supplier either find a like replacement for the power the unit is unable to provide or require the owner to make the payments necessary to hold harmless all market participants for its failure to meet its contractual obligations. Making the relationship between a specific market rule violation and the penalties assessed as transparent as possible achieves two goals. First, it limits the opportunities for the system operator and regulator to exercise discretion in setting penalties. Second, it allows market participants to formulate the best possible cost-benefit assessment associated with a specific market rule violation.

The third guideline is that the penalty associated with a market rule violation should not exceed the harm this market rule violation causes to all market participants. This guideline addresses the tendency regulators often have to set penalties sufficiently high to deter market participants from engaging in behavior that has any likelihood of violating the market rules. Excessive penalty levels have a cost. They cause market participants to focus on avoiding being penalized for a market rule violation rather than on producing electricity in a least-cost manner or purchasing wholesale electricity in a least-cost manner. For example, setting the penalty for failing to respond to a dispatch instruction too high could cause suppliers to avoid participating in the wholesale market or to downgrade the maximum amount of energy they are willing to sell from each of their units.

\section{Behavior Detrimental to System Reliability and Market Efficiency}

This section describes a general mechanism for determining if a supplier engages in persistent behavior detrimental to system reliability and market efficiency and what the appropriate standards are for determining when market operations should be suspended. Real-time electricity markets are, by definition, centralized market mechanisms where the actions of some market participants can impact the ability of other market participants to sell their output or buy the energy necessary to serve their retail customers. For many of the same reasons that there can only be one air traffic controller for each airport, there can only be a single real-time market operator for each transmission network. The need to deliver power through a common transmission and distribution network suggests that all market 
participants have a common interest in preventing behaviour that significantly degrades system reliability and market efficiency because it reduces their expected profits from participating in the wholesale market.

This aspect of the regulatory process addresses the concerns about harmful market outcomes typically voiced by parties claiming market manipulation. However, it avoids what I believe to be the impossible task of demonstrating that a market participant manipulated the market. As noted earlier, whether actions constitute market manipulation depends on one's perspective. Viewed from one perspective, all suppliers that attempt to impact the price they are paid through their own unilateral actions are engaging in market manipulation. The extent of unilateral market power possessed by a supplier is typically measured by its ability to move market prices through its unilateral actions. Consequently, a blanket prohibition of market manipulation written into the market rules seems to prohibit suppliers from maximizing profits given the actions of their competitors. These actions can lead to market outcomes that benefit consumers when all suppliers face sufficient competition. This logic is why there is no explicit prohibition against market manipulation under US antitrust law-it amounts to prohibiting behavior that is a major driver of the benefits in competitive markets.

The prohibition of behavior that is detrimental to system reliability and market efficiency focuses on identifying and eliminating detrimental behavior by market participants, rather than on punishing this behavior. Penalties and sanctions are a last resort, when all other options for eliminating the behavior have been tried; including asking the market participant to stop because of the significant harm this behavior is imposing on other market participants.

There is a potential downside to giving the regulator the ability to make such a finding. To the extent that the regulator is influenced by the political environment, it may be tempted to intervene to pursue political ends rather than allow politically favored electricity retailers to pay higher prices for electricity or politically favored suppliers to receive lower prices for the electricity they produce. That is why the regulator must follow a well-defined process before it is allowed to make a finding of persistent behavior harmful to system reliability and market efficiency and to suspend market operations temporarily.

The major difficulty associated with implementing this market rule is that the regulator would have to infer from a market participant's behavior whether its bidding, scheduling, or operating behavior intended to harm system reliability or market efficiency. If the regulator identifies behavior that is detrimental to system reliability, and has clear evidence (for example, a whistleblower or internal correspondence) that the market participant engaged in this behavior with full knowledge that it significantly harmed system reliability or market efficiency, penalties may be imposed without first going through the administrative process described below.

However, it seems very unlikely that the regulator would have direct evidence of intent, particularly if there is a market rule that imposes significant penalties on the market participants that have been shown to have engaged in this type of behavior. Enforcing a "behavior detrimental to system reliability and market efficiency" provision is more difficult 
if this market rule also imposed the very reasonable requirement that this detrimental behavior must also have a significant impact on market outcomes. This would require the regulator to make the often very subjective determination of what constitutes a "significant" market impact. Despite these difficulties with determining "intent" and "significant market impacts," an administrative procedure along the lines discussed below can adequately address these complications in making the finding of "intent to impose significant harm."

A necessary first step in any process for determining intent is the ability to demand and receive information from market participants. This reinforces the need for a pre-condition for participation in the wholesale market that each entity agree to provide, in a timely manner, all information necessary for the regulator to undertake an investigation of intent to impose significant harm to system reliability or market efficiency. As discussed above, this agreement to provide information should be subject to the constraints that the information request is necessary to undertake the current investigation and does not impose costs on the market participant that are out of line with the alleged harm that the market participant is imposing.

The regulator should implement the following multi-stage process for determining intent and imposing penalties commensurate with the harm caused by these actions. It is counterproductive for the regulator to prohibit actions that are difficult to define and even more difficult to determine if they occur. For the same reasons that I believe it is impossible to prove market manipulation, it equally difficult prove that a market participant is gaming the market or engaging in false scheduling, meaning that it is buying energy that it does not intent to consume or selling energy it does not intent to produce. Market rule prohibiting behavior harmful to system reliability and market efficiency should prevent the harm that many observers believe is the result of market manipulation, gaming or false scheduling.

Prohibiting behavior without first finding "intent" and "significant harm" will cause market participants to avoid actions that often enhance market efficiency and system reliability that might be interpreted as one of those prohibited. Instead, the regulatory process for determining intent should recognize that it is extremely difficult to distinguish legitimate profit-maximizing behavior from actions that intend to harm system reliability and market efficiency without some exchange of information between market participants and regulator. In addition, behavior that might be interpreted by some observers as gaming or market manipulation is often rendered unprofitable by the actions of other market participants. Consequently, these sorts of market efficiency or system reliability problems can often be solved through information provision to the market at large, thereby eliminating the need for further action.

A key feature of this market rule is a transparent process for identifying intentional behavior detrimental to system reliability or market efficiency. This should include a process for taking the actions necessary to stop this behavior or the harm that it causes. The focus of this process should be on stopping as quickly as possible intentional behavior that the regulator determines causes significant harm to market efficiency and system reliability.

The first step in this process is therefore to identify behavior that is likely to harm to market efficiency and system reliability. Two findings are necessary for the process to 
continue to the next step. The regulator must first determine if this behavior is persistent, and if it has the potential to impose significant harm either because it is very persistent or extremely harmful when it does occur. The next stage of the process involves alerting all market participants to the existence of this behavior and publicly disclosing the identity of the market participant engaging it. The goals of this stage of the process are to subject this market participant to public scrutiny and to provide all market participants with information that they can use to take actions that attempt to render this behavior unprofitable.

Public disclosure is a very important step in the process of determining intent because all market participants, including the market participant engaging in the behavior, know that the regulator has publicly stated that this behavior is harmful to system reliability or market efficiency. Consequently, continued behavior by this market participant that imposes significant harm provides strong evidence in favor of a finding of intent.

In most cases, this stage of the process should put an end to the behavior or the harm it causes. However, in those instances when the actions are sufficiently profitable to the market participant or group of market participants that they continue to cause significant harm, the regulator should initiate a formal investigation of intent. To do this the regulator needs the ability to request and receive in a timely manner the information from the offending market participant necessary to make a credible determination of intent to impose harm. An important goal of this information gathering effort is for the market participant to provide information to the regulator demonstrating that there is no direct causal link between market participant's behavior and harm to system reliability or market efficiency.

If the regulator's information gathering efforts reveal substantial evidence of a direct causal link between this market participant's behavior and the presumed harm, then the regulator should find that this market participant did intend to harm system reliability or market efficiency. If there is an affirmative finding of intent, the regulator may need to collect additional information to determine the appropriate magnitude of penalties. If the regulator makes an affirmative finding of intent it would then be required to set the appropriate level of penalties. The results of the investigation and the regulator's rationale for its recommended level of penalties should be subject to judicial review.

As should be clear from the above discussion, the major focus of this process is on eliminating the harmful behavior as soon as possible, not on assigning blame or imposing penalties. Only when public disclosure of the actions and the regulator's own investigation fails to stop or eliminate the harm associated with this behavior should the regulator attempt to determine intent and assign penalties for this behavior.

To guard against the possibility that there may be circumstances when the unilateral profit-maximizing actions of market participants can lead to enormous harm to consumers, the regulator should have the ability to suspend market operations temporarily. An example of such a mechanism is the "guardrails-to-competition" approach discussed in Wolak (2003d). This mechanism relies on the competitive benchmark analysis discussed in BBW (2002). It sets a prospective measure of the extent to which electricity prices over a rolling 12month horizon can exceed the competitive benchmark level. If the difference between the quantity-weighted average market price over the previous 12 months exceeds the quantity- 
weighted average competitive benchmark price computed using the methodology outlined in BBW (2002) over the previous 12 months by more than $\$ 5 / \mathrm{MWh}$, then an automatic regulatory intervention would be triggered. In Wolak (2003d), I argue that this intervention should be a 12-month period of cost-of-service prices for all suppliers. The idea behind this intervention is that it is viewed as sufficiently Draconian, yet credible to implement, so that suppliers never allow this guardrail on competition to be violated. For example, rather than exercise substantial market power in the spot market, a supplier will sign forward contracts or other spot price hedging arrangement to improve spot market performance before these guardrails are exceeded.

\section{Coordinating Antitrust and Regulatory Policy}

This section concludes with a brief discussion of how the industry-specific regulatory process should interact with the antitrust authority. The primary concern of the regulatory process is protecting against the economic harm associated with unilateral exercise of market power. Antitrust policy is concerned with detecting coordinated actions to raise prices and combinations (typically mergers) that result in a substantial lessening of competition. Antitrust law also prohibits attempts to monopolize, but this is unlikely to be relevant to the electricity industry beyond its implications for merger analysis. As discussed in Section 2, from the perspective of other industries, the concentration levels in the wholesale and retailing segments of the electricity industries in most countries appear fairly competitive. The transmission and distribution segments are price-regulated by the industry-specific regulator, so it is difficult to see how a firm could monopolize this industry except through mergers, or because of a poorly designing industry-specific regulatory process. Given these roles, the industry-specific regulator should primarily serve a support function to the antitrust process, with the antitrust policy functioning independent of the industry-specific regulatory process.

This hierarchical relationship implies that the industry-specific regulator is the first line of defense for consumers against harmful market outcomes. While the industry-specific regulator may wish to approve mergers, this seems redundant if the antitrust authority does a thorough review. Given the expertise of the industry-specific regulator, a thorough review would require the antitrust authority to solicit extensive input from the industry-specific regulator, including the provision of industry-specific data that is part of the ongoing regulatory process. The industry-specific regulator would also be a key source of information for making a determination of "coordinated behavior in restraint of trade" by industry participants.

It is possible that actions by the regulatory process could have the unintended consequence of assisting market participants in coordinating their actions to raise prices or in facilitating the attempts of a firm to monopolize a market. For example, bringing market participants together to discuss their costs of production and how they operate their generation facilities, as FERC often did during the former vertically-integrated regime, can improve the efficacy of the regulatory process. However, in a wholesale market regime, these sorts of meetings have the potential to substantially harm competition. This potential for the regulatory process to facilitate violations of antitrust law implies that the antitrust authority must clearly specify protocols governing multi-lateral meetings between market 
participants and the regulatory authority. However, two outstanding antitrust issues are whether the industry-specific regulator can be held liable for inadvertently facilitating antitrust violations and whether market participants should be held harmless for antitrust violations that are the direct result of this behavior by the antitrust authority. Particularly, in the US, this issue has become increasingly relevant as the industry-specific regulator has more actively intervened in the day-to-day operation of the wholesale market.

Despite this potential for the industry-specific regulator to facilitate antitrust harm, I am extremely skeptical that the antitrust authority can eventually replace the industry-specific regulator, because antitrust law is not concerned with the unilateral exercise of market power that causes significant consumer harm, which has historically been a major problem in wholesale electricity markets. However, as market participants become more sophisticated, the need for a number of regulatory safeguards is likely to diminish.

Once the price cap on the spot market is increased to a level where it is only occasionally hit and a liquid forward market for energy develops, there is less of a need to monitor the level of forward contracting and mandate minimal levels of coverage for electricity retailers. Although it is unclear at what level of the price cap this change in regulatory oversight should occur, the necessary level is clearly above the highest price cap that currently exists in all of the US markets of $\$ 1000 / \mathrm{MWh}$. To the extent that local market power mitigation mechanisms are incorporated into the market rules in an easily enforceable manner, there is less need for the industry-specific regulator to be involved in this process.

It is difficult to see how the need for industry-specific regulator to price transmission and distribution services can be eliminated. Although an administrative process for allowing new generation units to interconnect to the transmission network could be written into the market rules, determining when and where competition-enhancing transmission upgrades should take place and whether they have expected benefits to market participants that exceed their cost is a sufficiently complex and subjective process to require regulatory oversight far into future. I would expect that as policymakers obtain a better understanding of the competition-enhancing benefits of transmission upgrades, the industry-specific regulator will be given more authority to manage the transmission network. Because so many markets outside of the US began operation with significant over-capacity in their transmission network, this has not been major issue. However, a forward-looking pro-active transmission expansion policy can limit the frequency that LMPM mechanisms that distort market outcomes must be relied upon. The industry-specific regulator has the expertise and legal mandate to manage the transmission network to maximize the economic benefits from a competitive wholesale market.

The other circumstances under which I would expect a significantly reduced role for the industry-specific regulator is if there was a substantial reduction in both the system-wide and local concentration in generation ownership. For example, divestiture of generation capacity down to the unit level (there are typically multiple generation units at a power plant) would significantly reduce virtually all of the unilateral market power concerns expressed above. Given the size of the financial returns that existing suppliers earn from the current concentration and geographic distribution of generation unit ownership and the likely economies to scope and scale associated with operating multiple generation units at a 
given location, it is very unlikely that such an outcome could be implemented in any existing wholesale market. Consequently, industry-specific regulators need not fear for their jobs, because there is much for them to do in the future. 


\section{References}

\section{(All references marked with $\left(^{*}\right)$ are available at http://www.stanford.edu/ wolak)}

Borenstein, Severin, Bushnell, James and Wolak, Frank A. (2002) "Measuring Market Inefficiencies in California's Restructured Wholesale Electricity Market," American Economic Review, December, 1367-1405.(*)

Bushnell, James and Saravia, Celeste (2002) "An Empirical Assessment of the Competitiveness of the New England Electricity Market," May, Center for the Study of Energy Markets Working Paper Number CSEMWP -101, available from http://www.ucei.berkeley.edu/pubs-csemwp.html

Mansur, Erin T. (2003) "Vertical Integration in Restructured Electricity Markets: Measuring Market Efficiency and Firm Conduct," October, Center for the Study of Energy Markets Working Paper Number CSEMWP-117, available from http://www.ucei.berkeley.edu/pubs-csemwp.html.

Wolak, Frank A. and Patrick, Robert H. (1997) “The Impact of Market Rules and Market Structure on the Price Determination Process in the England and Wales Electricity Market," February. $\left(^{*}\right)$

Wolak, Frank A. (1999) "Market Design and Price Behavior in Restructured Electricity Markets: An International Comparison," in Competition Policy in the Asia Pacific Region, EASE Volume 8, Takatoshi Ito and Anne Krueger (editors) University of Chicago Press, 79-134.(*)

Wolak, Frank A. (2000a) "An Empirical Analysis of the Impact of Hedge Contracts on Bidding Behavior in a Competitive Electricity Market," International Economic Journal, Summer, 1-40. $\left({ }^{*}\right)$

Wolak, Frank A. (2000b) "Comments on the Office of Gas and Electricity Markets (Ofgem) License Condition Prohibiting Abuse of Substantial Market Power," submission to United Kingdom Competition Commission, July. $\left.{ }^{*}\right)$

Wolak, Frank A. (2003a) "Measuring Unilateral Market Power in Wholesale Electricity Markets: The California Market 1998 to 2000," American Economic Review, May 2003, 425-430.(*)

Wolak, Frank A. (2003b) "Diagnosing the California Electricity Crisis," The Electricity Journal, August, 11-37. $\left(^{*}\right)$

Wolak, Frank A. (2003c) "The Benefits of an Electron Superhighway," Stanford Institute for Economic Policy Research Policy Brief. November. $\left({ }^{*}\right)$ 
Wolak, Frank A. (2003d) "Sorry, Mr. Falk: It's Too Late to Implement Your Recommendations Now: Regulating Wholesale Markets in the Aftermath of the California Crisis," The Electricity Journal, August, 50-55. 